\section{Ligation of the thoracic duct through transabdominal phrenotomy for chylothorax after heart operations}

\section{To the Editor:}

Chylothorax is a rare but ominous complication after heart operations.' When conservative treatment does not succeed, surgical ligation of the thoracic duct through right thoracotomy is usually indicated. Sometimes, however, it is difficult to identify the thoracic duct through the thoracotomy; in such cases, mass ligation between the aorta and azygos vein is commonly performed. ${ }^{2}$ Recently, we ligated the thoracic duct through transabdominal phrenotomy, which proved to be a useful way to expose and visualize the duct.

The patient was a 5-year-old boy with tetralogy of Fallot. Intracardiac repair was performed through a median sternotomy with cardiopulmonary bypass. The procedure was uneventful and the postoperative hemodynamic parameters were stable except that chylothorax of the right side became manifest on the second postoperative day, necessitating a large volume replacement. Because the lymphorrhea persisted without any reduction of drainage amount, surgical ligation of the thoracic duct was indicated on the eighth postoperative day. We were hesitant to approach the repair through a right thoracotomy because the patient had a slight fever and the chest x-ray film showed a pneumonitis-like shadow in the right lung field. We therefore decided to use a transabdominal approach. The patient was placed under general anesthesia in the supine position and a transverse incision was made on the upper abdominal wall. On entering the peritoneal cavity, we divided the falciform ligament. The lateral segment of left hepatic lobe was detached from the peritoneum and was retracted to the right. A vertical incision was made to the diaphragm at the right anterior portion of the esophagogastric junction. Then the posterior mediastinum was entered and the esophagus was encircled by a tape and was retracted to the left. By dissecting the space between the aorta and the azygos vein at anterior aspect of the vertebral body, we could clearly visualize the thoracic duct and ligated it easily. Thereafter the chylothorax subsided and the patient recovered well and was discharged from the hospital.

Unlike with the lymphorrhea after lymph node dissection in an operation for carcinoma, a simple ligation of the thoracic duct just above the diaphragm is usually sufficient to abate chylothorax resulting from a heart operation. To our knowledge, the transabdominal approach has never before been reported. We wish to stress that ligation of the thoracic duct through transabdominal phrenotomy is feasible; it is especially useful when there is an inflammatory lesion or an adhesion in the right hemithorax.

Haruo Miyamura, $M D$ Hiroshi Watanabe, MD Shoji Eguchi, $M D$ Tsutomu Suzuki, MD Department of Thoracic and Cardiovascular Surgery Department of Surgery Niigata University School of Medicine Niigata, Japan

\section{R EFERENCES}

1. Higgins CB, Mulder DG. Chylothorax after surgery for congenital heart disease. J ThORAC Cardiovasc Surg 1971;61:411-8.

2. Milsom JW, Kron IL, Rheuban KS, Rodgers BM. Chy- lothorax: an assessment of current surgical management. $\mathbf{J}$ Thorac Cardiovasc SuRg 1985;89:221-7.

\section{Heart operation in a patient with refractory idiopathic thrombocytopenic purpura}

\section{To the Editor:}

A 69-year-old man with severe proximal left anterior descending coronary artery disease was referred for a coronary artery operation after two attempted angioplasties resulted in early restenosis. Preadmission screening revealed severe thrombocytopenia (platelet count $63 \times 10^{9}$ cells/L). Current medications were atenolol, isosorbide mononitrate, nifedipine, frusemide, and amiloride. The patient was referred for hematologic investigation.

Bone marrow aspiration revealed active normal marrow with plentiful megakaryocytes, consistent with peripheral platelet destruction. Results of indirect platelet antibody tests and assay for antinuclear factor were negative. A presumptive diagnosis of idiopathic thrombocytopenic purpura was made. Therapy with prednisolone ( $1 \mathrm{mg} / \mathrm{kg}$ per day) was commenced in an attempt to obtain remission before operation, but this regimen resulted in only small, transient increases in the platelet count. Because of this complication, the patient was admitted to the hospital and intravenously given monomeric immunoglobulin (Sandoglobulin) at a dose of $0.4 \mathrm{gm} / \mathrm{kg}$ daily for 5 days, commencing 5 days before the proposed date of operation. The patient's platelet counts before and after operation were as follows: preoperative day $5,7 \times 10^{9}$ cells $/ \mathrm{L}$; preoperative day $3,37 \times 10^{9}$ cells $/ \mathrm{L}$; day of operation, $64 \times 10^{9}$ cells $/ L$; postoperative day $1,157 \times 10^{9}$ cells/L; postoperative day $2,140 \times 10^{9}$ cells $/ \mathrm{L}$; and postoperative day $10,141 \times 10^{9}$ cells $/ \mathrm{L}$.

At operation, full cardiopulmonary bypass was used with aortic crossclamping and crystalloid cardioplegia. Saphenous vein was used to graft the left anterior descending coronary artery. Bypass time was 30 minutes and clamp time was 14 minutes. From the time the sternum was wired to the time the mediastinal drain was removed ( 20 hours), remarkably there was no drainage.

Adult idiopathic thrombocytopenia purpura is an autoimmune condition arising from antibody binding to the glycoprotein IIb-IIIa complex on the platelet membrane. Antibodycoated platelets are prematurely removed from the circulation by attachment to macrophage Fc receptors, followed by phagocytosis. Reduced platelet life span results in an increase in the megakaryocyte mass and the platelet turnover (two to eight times normal). 'The mechanism of action of intravenously administered immunoglobulin is not entirely clear, but a major effect is likely to be the blockade of macrophage Fc receptors so that the antibody-coated platelets are not recognized or destroyed. ${ }^{2}$ The increased platelet production is thus unopposed and large, young platelets, which are highly effective in hemostasis, are released into the circulation. This case serves as a further illustration of the effectiveness of the intravenous administration of monomeric immunoglobulin in the management of patients with idiopathic thrombocytopenia purpura refractory to steroid treatment.

N. P. Briffa, $M B, F R C S$ J. A. Dyde, $M B, F R C S$

R. I. Harris, $M B, M R C P, M R C P a t h$

Departments of Cardiothoracic Surgery and Hematology Walsgrave Hospital Coventry, England 